INTERNATIONAL DESIGN CONFERENCE - DESIGN 2018

https://doi.org/10.21278/idc.2018.0362

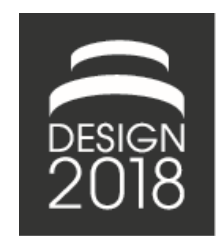

\title{
MODEL-DRIVEN VALUE ASSESSMENT: A CASE FROM THE FOOD PACKAGING INDUSTRY
}

\author{
M. Bertoni, S. A. Chowdhery and A. Bellini
}

\begin{abstract}
Consumer perception of food packaging solutions is driven by early design decisions on paperboard configuration and manufacturing technologies. Simulation Driven Design is common to frontload design activities, but is confined to the engineering field and fails to capture higher-level value aspects. This paper presents an assessment framework connecting customer value dimensions with simulations conducted on the mechanical properties of the packaging material, and discusses how value modelling results can be visualised to support collaborative decision making in cross-functional teams.
\end{abstract}

Keywords: case study, conceptual design, value driven design, design models, visualisation

\section{Introduction}

The food packaging industry has undergone a deep transformation in the last decades, with consumers wanting to have more functionalities and greater convenience in their packaging (e.g., Coles et al., 2003, Wang, 2013). Consumers' perception of packaging solutions can eventually be traced back to early stage decisions concerning raw materials and paperboard configuration (Sand, 2010). The fine-tuning of the latter has a great impact at system level, both on the performances of the entire value chain and on the behaviour of consumers. The introduction of new packaging material configurations requires much prototype development and physical/virtual testing, which is a long and costly process. Increasing effectiveness of early-stage design decisions is critical to reduce lead time and cost of the development process and to increase the quality of its outcomes. Finite element modelling (FEM) is a natural support to this task and is extensively used to downselect concepts, before investing too many resources on a sub-optimal package design (Andreasson and Jönsson, 2014).

However, geometrical models, FE simulations and blueprints do not raise awareness about the end game solution and do not consider all relevant aspects of value for the product, such as packaging trends, fashions, recycling and more (Singh et al., 2012; Rundh et al., 2016). Knowledge from different disciplines (e.g., marketing, finance, aftersales) needs to be combined to identify the most valuable configuration, and the design team shall be supported in the process of identifying and negotiating tradeoffs from a lifecycle perspective. Hence, the use of modelling and simulation support shall be expanded from the prediction of technical product features as a function of different combinations of design variables, to the prediction of value-related aspects for business-to-business customer and end-users.

The aim of this research work is to explore the use of a model-driven approach to enable the assessment of the value produced by alternative packaging material configurations in early design. The ambition is to create a chain of models, from raw material to consumer experience, which can generate (by simulation) the necessary information on how much customers and consumers value certain capabilities against each other, to eventually improve multidisciplinary understanding in early design. The main research question driving the work can be described as: 
- How to support decision-makers in assessing the value of early stage design concepts, increasing awareness of unspoken needs, estimated performances, and impact of contextual conditions on product operations?

The objective of the paper is to present an assessment framework to connect high-level aspects of value with simulations and analysis conducted on the mechanical properties of the packaging material. Furthermore, the paper introduces and discusses the development of an environment where to visualize the outcomes of the value analysis. This environment is intended to link the results of value modelling activities with requirements and material information, with the final goal to support collaborative decision making in cross-functional teams.

\section{Methodology}

The paper presents the findings of applied research based on a single case study approach (Yin, 2013). The research is conducted in collaboration with a multinational food packaging and processing company based in Sweden. The company offers packaging, filling machines and processing for dairy, beverages, cheese, ice-cream and prepared food, including distribution tools. The overall research effort can be framed into the Design Research Methodology (DRM) framework (Blessing and Chakrabarti, 2009). DRM consists of four stages: Research Clarification (RC), Descriptive Study I (DS-I), Prescriptive Study (PS) and Descriptive Study II (DS-II). The research presented in this paper covers a review-based RC, a comprehensive DS-I and an initial PS.

Following the guidelines for qualitative research proposed by Miles et al. (2013), the research question was iteratively developed from the conceptual framework developed under the RC stage. The question guided the sampling plan for the interviews and the development of the coding scheme for the analysis of the transcripts. Data collection activities featured 8 semi-structured interviews, which were conducted between May and November 2017. The sample covers a variety of roles, both at managerial and engineering level. In line with what suggested by Ritchie et al. (2013) for small-scale, in-depth studies, respondents were located by means of non-probability sampling. This means that they were selected 'with a purpose': experience with modelling and simulation and with design decision gate meetings were considered the main criteria for purposive selection.

The analysis of internal company documentation and multi-day physical co-creation workshops served as triangulation method. In these workshops the authors compiled visual representations and demonstrators of the emerging modelling concepts, which were verified with company stakeholders to identify critical topics for modelling. Reflective learning was further aided by the participation in regular debriefing activities. Findings were also iteratively discussed and validated with a broader set of industrial practitioners in co-located research workshops.

\section{Model-driven value assessment: Trends and challenges}

Literature recognizes the importance of models as a means for verification, but also stresses the need for a broader view on how these are used to support new product development, i.e., using models and simulations to learn about 'what' to develop, rather than to merely verify if a design does not fail regarding performance (e.g. Isaksson et al., 2009). Enhancements in computer-based product modelling and simulation promote parallel experimentation, where multiple designs can be assessed iteratively while avoiding early commitment to a specific concept. This raises awareness of behaviour and performances of a design, identifying potential failures as well as improvements.

A simulation-driven design (SDD) paradigm (Sellgren, 2004) is becoming more common in the manufacturing industry to 'frontload' (Thomke and Fujimoto, 2000) engineering design activities. In the packaging industry, Finite Element Methods (FEM) are increasingly used proactively - rather than reactively and late in the development process - to facilitate early stage design decisions (Andreasson and Jönsson, 2014), for instance in the development of package opening solutions (Islam et al., 2016). Models are built and executed at multiple length scales (e.g., microscopic level, subsystem level and at a macroscopic application level), and researchers are starting to bridge the different length scales in the application. However, SDD remains often confined to material and mechanical properties (Panarotto et 
al., 2017) and a gap exists with regards to creating a chain of models able to render a broader picture of the value of design solutions since an early design stage.

\subsection{Value assessment: Quantitative vs. qualitative models}

Isaksson et al. (2015) explain that engineering value-added systems means for practitioners to look at design trade-offs from the perspective of how much customers 'value' certain capabilities against each other. Monetary units are often regarded as the most convenient, practical and universally understood metrics to resolve trade-offs in system design. The monetary value of an engineering system is often computed as Surplus Value (SV), which is the price paid by the customer that makes the net present value of the transaction to be zero (Price et al., 2012). The SV function captures revenues and costs items along the system lifecycle, extending beyond manufacturing cost and performance, to consider all the 'ilities' of a system (McManus et al., 2007) and intangible/subjective factors.

In situations where qualitative data and assumptions prevail, such as in early design, it is often preferable to apply Multi Criteria Decision Analysis (MCDA) techniques to the value assessment problem. An issue in MCDA is defining appropriate value criteria from the initial list of needs. The 'main headings' for design evaluation proposed by Pahl and Beitz (1996, p. 179), together with the hierarchical structure of needs (primary, secondary, tertiary) from Voice-of-the-Customer theory, spotlight macro-categories from which to extract criteria for the MADM exercise. Other major frameworks from which value criteria can be derived are the Value Proposition Canvas (VPC) (Osterwalder et al., 2014) and the Desirability-Feasibility-Viability (DFV) framework from the Design Thinking methodology (Leavy, 2010). The Triple Bottom Line (TBL) (Willard et al., 2012) model complements the above by forcing decision makers to reflect on value creation from 'social', 'environmental' and 'financial' point of view.

\section{Descriptive study findings}

Food and beverage packages are produced with different shapes, sizes and materials. They are built from a functionally layered composite made of:

- a thick (about $500 \mu \mathrm{m}$ ) paperboard ply that confers stiffness, stability and strength to the package, bearing the load when the package is filled, folded and gripped, and that provides the necessary support for printing;

- a thin $(10 \mu \mathrm{m})$ aluminium foil, which acts mainly as oxygen and light barrier;

- a low-density polyethene (LDPE, $30 \mu \mathrm{m}$ ) film that protects paper and print from moisture-related damage, seals in the liquid, avoids contamination, facilitates hermetical closure, and enables adhesion between the layers.

The descriptive study showed that the development of a new packaging solution presents a complicated, interdisciplinary set of challenges including the interaction of packaging and fillgoods, dynamic processes, and mechanical components of packaging and packing equipment. For this reason, the introduction of a new packaging material configuration is a costly and time-consuming process, which takes on average 2 months from the earliest idea generation stages to the physical tests for a new packaging configuration.

A main concern for the design team is that the characteristics of the package system are highly dependent on how the manufacturing process is configured. The production of packages involves several steps, where layers are assembled together by thermo-mechanical action and some of the polymers are melted during manufacturing. Different temperature and pressure values in the process influence the behaviour of the paperboard and aluminium foil, rendering different mechanical properties in the machine direction and cross direction, causing defects and cracks. What can be done in the manufacturing line or in the material structure to obtain the desired level of customer value and end-user satisfaction is a concern in early-stage decision making.

A main concern for the engineering team is to be able to execute quick what-if analysis of alternative configurations already in the project fuzzy front end, to filter out options that "do not work". This "do not work" expression was further cascaded down to concerns related to the opportunity of having "customers at your fingerprints", to be able to assess if a given configuration will fulfil the expected level of performance and value. A wish emerging from the field work it to be able to test more efficiently 
the interplay between these factors, avoiding trial and error approaches. Modern computer technologies are increasingly used to fulfil this wish, both to explore the design space and optimize existing configurations. However, interviews and observations showed that early stage design decision making is a matter of interplay between different roles and functions in the organization, including both engineers and individual with a managerial role. Concerns have been raised by practitioners about the difficulty of communicating value-related aspects together with other properties and requirements during in the stage-gate process. An issue in this respect is that simulation models are not easily connected to the set of models used in the business domain. The analysis of the empirical data further highlighted the need of promoting value discussions between the individuals being part of the crossfunctional teams. These findings point to the need for an environment where to display the results of the value analysis and connect them to engineering issue, so to highlight which areas are contributing to given value dimensions.

\section{Development of a model-driven value assessment environment}

DS-I showed that value creation in the development of food packaging configurations includes 4 levels and 3 main transitions, which likens the Systems Engineering V-model (Figure 1):

- customer experience and value creation is highly influenced by both mechanical and barriers properties of the package 'system';

- these are affected by the outcome of creasing and folding activities conducted on the packaging material during the manufacturing process;

- these activities are influenced, in turn, by the atomic properties of the materials processed in the manufacturing line.

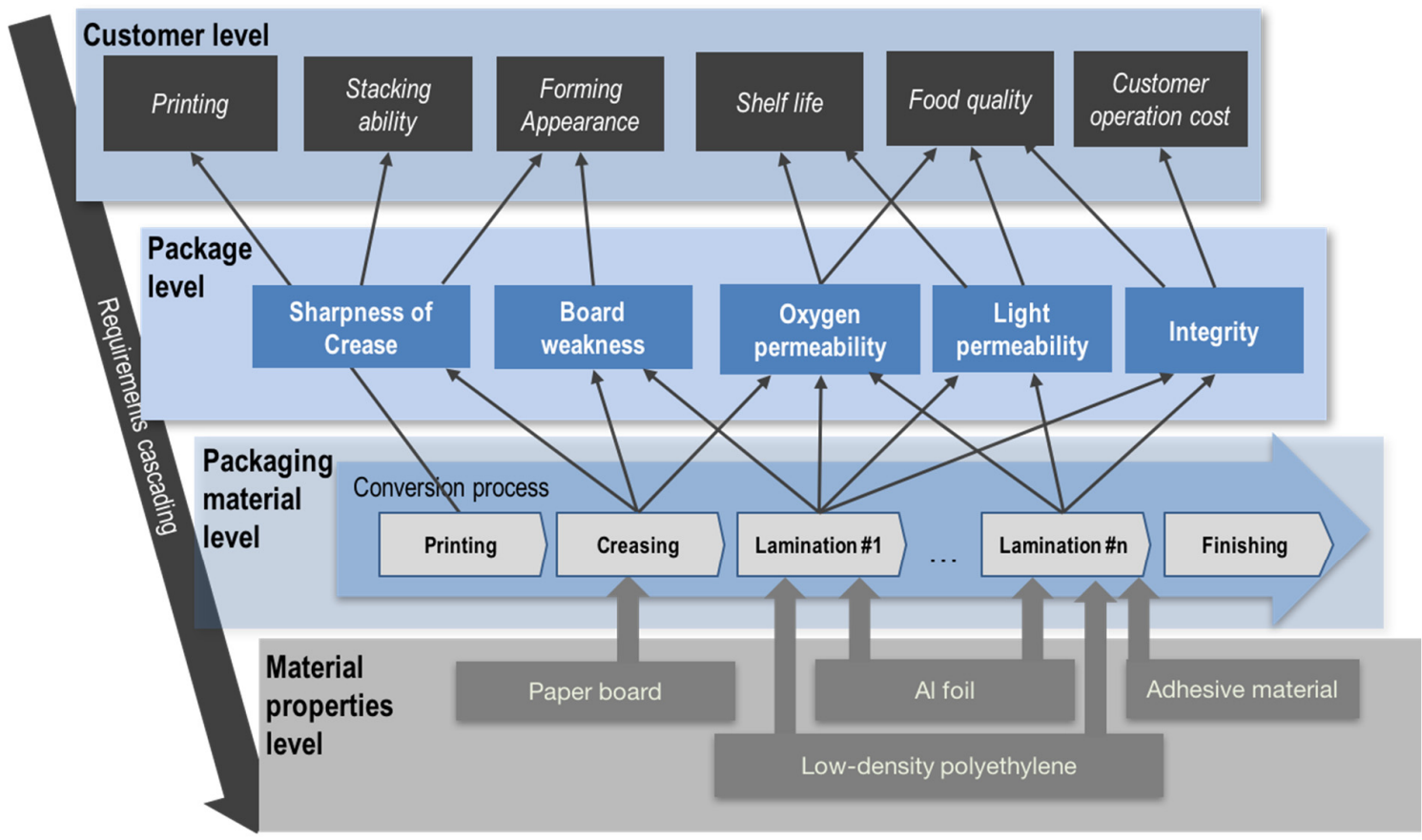

Figure 1. Model-driven value assessment framework with (simplified) model mapping

Arrows in the model represent correlations between models as found during the empirical study, meaning that the output from one model is taken as an input in the following model. Each model in the framework (which is, both statistical models and virtual engineering models) is treated as a black-box. The concept of black boxes implies that an object is viewed only in terms of its inputs, outputs and transfer characteristics, while its underlying mechanism and internal workings remain hidden. 


\subsection{From customer/consumer value to package properties}

The development of the assessment framework kicked-off by defining high-level drivers for customer and consumer value. A literature review highlighted the multi-faceted role played by packaging when it comes to consumer perceived value (e.g., Coles et al., 2003). This is not only understood as a means of protecting a product in the process of distribution, transport or storage (e.g., Rundh, 2009), but carries more values with regards to its ability to communicate with the environment (Wyrwa and Barska, 2017). The field data gathered from practitioners and experts (both engineers and managers) helped in refining the description and prioritization of the value dimensions for packaging solutions. Several of the areas above were discussed, with the most relevant for early-stage decision making being Shelf life, Food quality and Forming appearance, together with Customer operational costs, Printing and the ability to stack one package upon the other. Even if the proposed value drivers feature different degrees of priorities for the customers (i.e., some being more important than others, such as food quality) and are not linearly independent (e.g., packages with an extended shelf life have a positive impact on food quality), they were considered the most representative by the industrial experts to assess the value of packaging solutions at a customer level. DS-I brought to the identification main modelling areas for the package "system" influencing consumer experience and value: Sharpness of creases, Board weakness, Oxygen permeability, Light permeability and Board integrity (Figure 1).

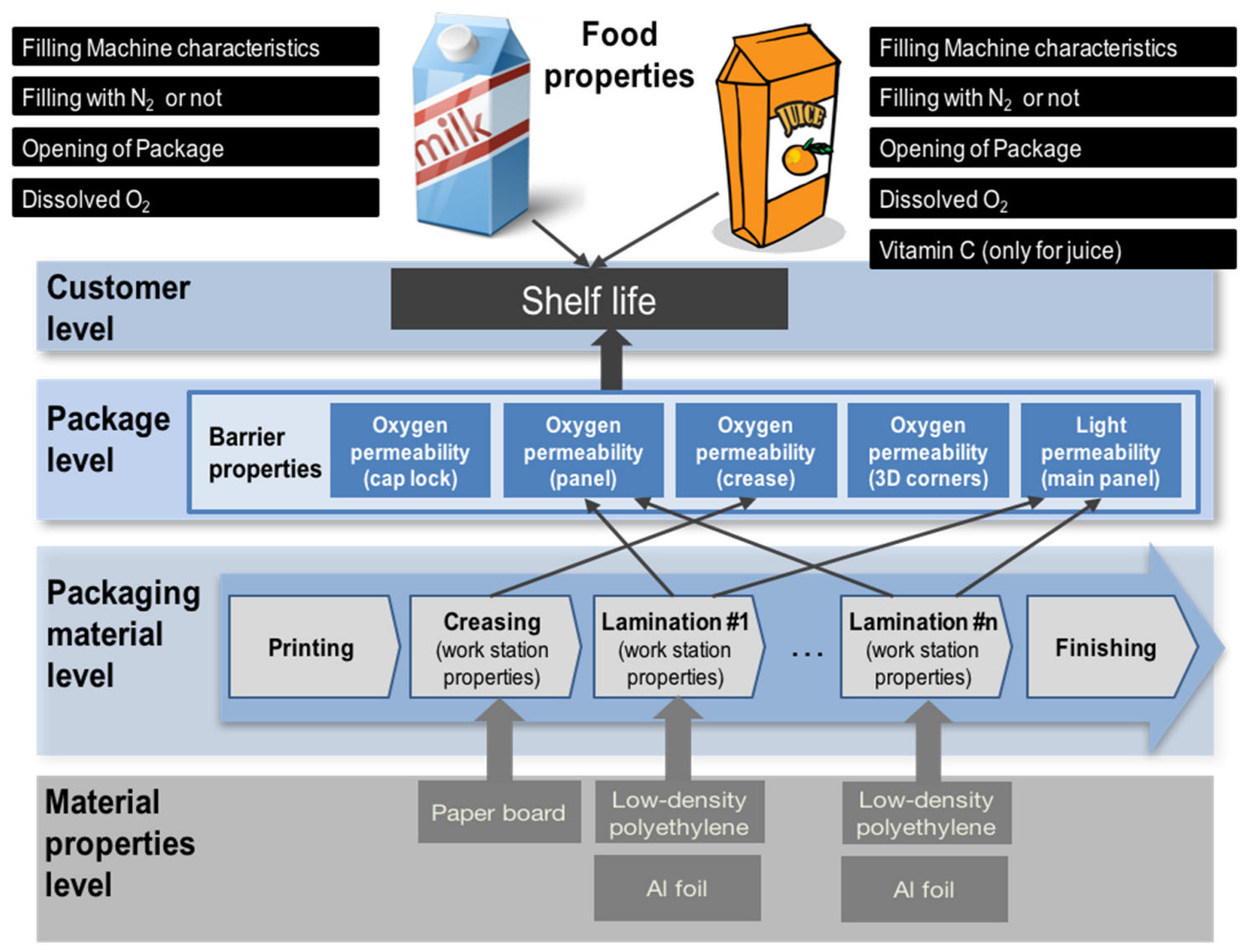

Figure 2. Linking material properties to shelf life in the value assessment model

A more illustrative example of how models are connected across levels relates to the issue of assessing 'shelf life' (Figure 2). In shelf life modelling, chemical reactions, biological degradation and mechanical properties are major inputs needed to obtain reliable predictions for food degradation. Shelf life modelling requires a list on input parameters to be executed, such as the concentration of oxygen or vitamin C (for juice), the use of nitrogen in the filling process, as well other characteristics related to the 
machine. At Package System level, shelf life is linked with 'Barrier Properties' of the package, which is also linked to food quality. These depend mainly on oxygen and light permeability in different zones of the package. To model how shelf life can be extended due to a new packaging configuration, oxygen permeability values for the flat laminated board, for the board corners and for the creasing lines are needed for the simulation. These values are further obtained by linking the model at the Packaging material level and to those at Material properties level.

\subsection{Linking package behaviour to material properties}

The Packaging Material level contains models that describe the outcome of creasing operations on the laminated multi-layered board. Creasing processes may be divided into 2 main families, twodimensional (2D) (between two panels) and three-dimensional (3D) (three crease lines combine at the corner) creases, which facilitate the 2D folds and 3D corner folds (Nygårds et al., 2009).

The empirical investigation showed that, once creasing operations are performed, the properties of the laminated structure change, affecting board weakness and possibly contributing to the formation of cracks in aluminium-foil. The latter causes issues with Integrity at Package System level, eventually affecting food quality and shelf life. Alternative configurations of the folding process (which is, insideinside fold, inside-outside fold and outside-inside fold.) may have different effects on the board weakness at the micro level (microstructure and fibre orientation), which translates into different barrier properties of the board at the macro level. Eventually, decisions concerning folding operations were found not only to be related to barrier properties issues and food quality, but also to have an influence on package 'appearance properties'. Interestingly, while weakness in the board is associated with food deterioration, it is a desirable feature to achieve good folding quality.

The Material property level is the primary input to all the models. Models at this level deal with the individual mechanical properties of the different layers of the board (aluminium foil, paperboard, LDPE and adhesive material), including microscopic and macroscopic phenomena. These properties play a significant contribution in terms of system performances. The consequences of decisions at this level (e.g., different layer thicknesses) propagated through the entire chain of models, ultimately affecting all value dimensions related to customers and consumers. For instance, aluminium foil properties influence the propagation of weaknesses in aluminium foil, which in turn allows the diffusion of oxygen in the package. Specific inputs for modelling activities at this level (i.e. young modulus and yield strength for aluminium foil and polymer) are gathered from suppliers, as well as by experimental means.

\section{Value visualization environment}

Figure 3 shows a mock-up of the value visualization environment realized in the Model-Driven Decision Arena (MDDA) (Bertoni et al., 2018b). The MDDA is a computer-based environment to support early stage design concept exploration. In the described case, the MDDA is used to display the cause-effect relationships that characterize the 3 transitions illustrated in the section above.

More than in producing an absolute number representing the value of a design, the descriptive study showed that practitioners are interested in understanding how a concept is positioned against relevant benchmarks, which is how much a solution is better or worse than previous options. Hence, the environment is designed to support comparative studies between a given baseline configuration and innovative proposals. Its main objective is to assist engineers and managers in negotiating features of innovative packaging configurations by conducting quick what-if value studies at varying material properties and process characteristics.

Figure 3 exemplifies how the cross-functional design team can interact with the MDDA to assess the behaviour and value of a package configuration during design exploration activities. After selecting the package type under analysis (bottom-left screen in Figure 3), decision-makers can modify material properties (e.g., layer thickness) for a given design option moving from an existing baseline (bottomright screen). In the example, models are used to calculate, from this input, the oxygen permeability performances of option \#n in different areas of the package (top-right screen). These results are benchmarked with the performances of the baseline, to facilitate trade-off negotiation. 


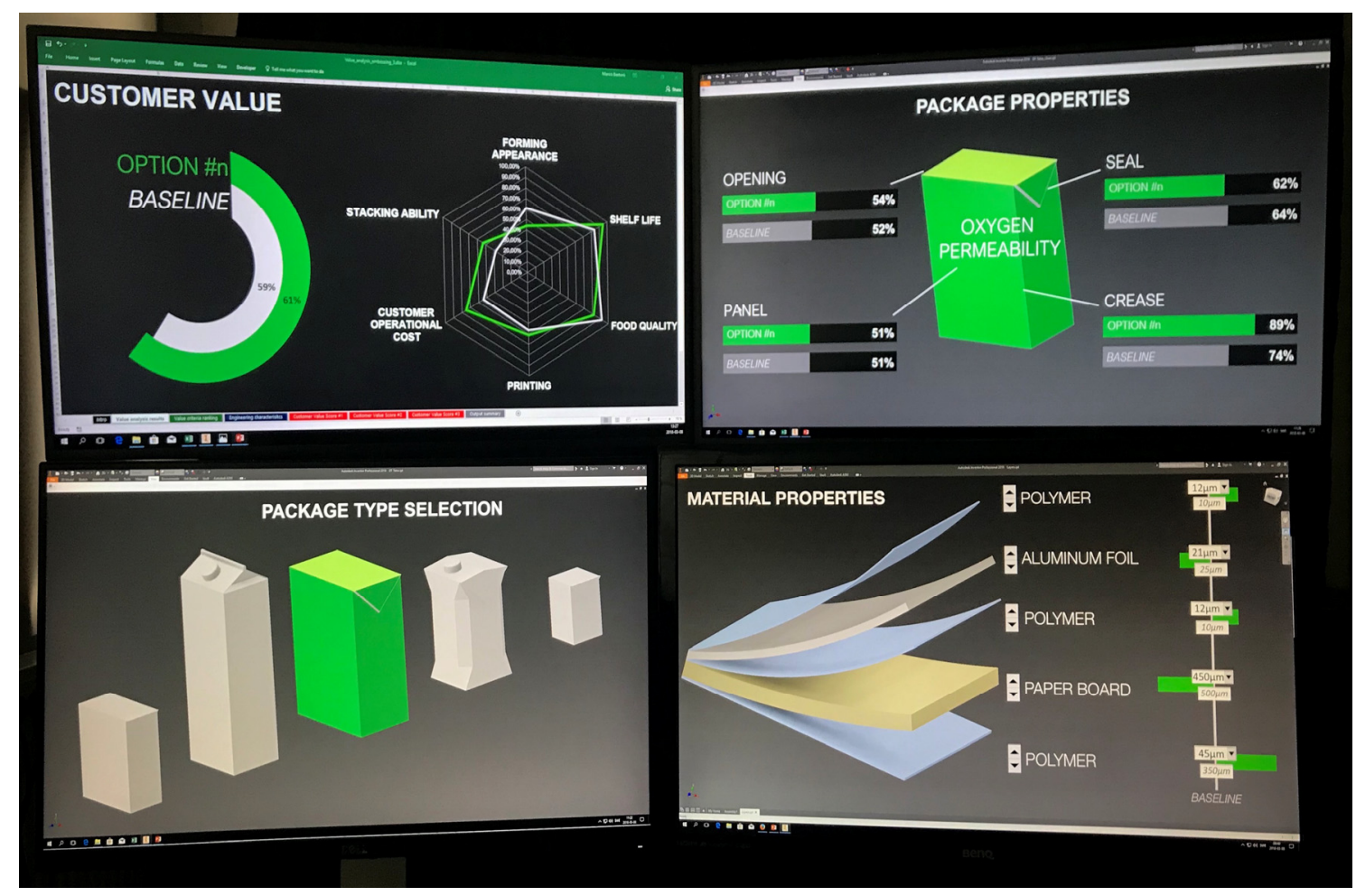

Figure 3. Value visualization environment mock-up in the MDDA

These data, together with the results of other similar models, are eventually aggregated in a 'customer value' view (top-left), where value assessment results along drivers of interest are displayed. The underlying value model in the proposed case mixes a quantitative and qualitative approach, with the latter being based on the Evoke method proposed by Bertoni et al. (2018a). Relevant value criteria for the MCDA exercise in Evoke are derived from the DFV framework (Leavy, 2010). Design merit scores (a concept borrowed from Eres et al., 2014) are obtained for each criterion of interest and for each analysed configuration. Ultimately, they are aggregated to render a total value score, which represents the 'goodness' (see: Cheung et al., 2012) of a design. By modifying the rank-weights of each criterion in the MCDA matrix, it is possible to assess the design for different strategies of value creation, which is for different markets or customer tiers.

\section{Discussion}

The main driving factor in the development of the environment is the opportunity to exploit a 'pool' of representations that mixes deterministic and qualitative aspects. Research in cognitive behaviours has shown that the human ability of processing information is increased when multiple cues are presented both across and within media/channels, ultimately leading to tasks being completed in less time and with less effort (Krikelis and Weems, 1994). This 'pool' is intended to facilitate negotiation in the crossfunctional teams, with some models being generic enough to be grasped by those stakeholders without a technical background, while others being specific enough to benchmark alternative concepts with sufficient confidence and detail. Observing the convergence between the different models helps the team in building an understanding of problems and solutions through associative processing.

A preference has been expressed towards techniques for browsing report results that display a limited set of criteria at a time, and that support information drill down for access to more detailed data. Studies have also shown an inverted U-shaped relationship between the efficiency of the decision-making task and the amount of information provided (Zanakis et al., 2013). Hence, in order not to overwhelm decisions makers with unnecessary details at the gate, the number of criteria to be presented at a time during the evaluation should be kept to a minimum, while providing enough information regarding strengths and weaknesses of proposed alternatives. 


\subsection{Verification with industrial experts}

Verification activities with the partner company showed that a main benefit of the proposed modelbased approach is that of providing an understandable picture of how different disciplines (from engineering to management) contribute to the creation of value for new products. Practitioners recognize that in the fuzzy front-end engineers are lacking tools to communicate why their work is 'good', and to deliberate about the most value-adding design. Hence, the proposed chain of models is acknowledged to cover a gap when it comes to stimulate value discussions across functions and organizational roles, as well as to maintain focus on the underlying business case, so that individuals can build arguments for selling their innovative ideas, both externally and internally.

The mapping activity is believed to be beneficial not only to explain what the models are doing in the system and how they are interacting with each other. It also serves the purpose of 1) answering questions at the production level, in terms of what changes are necessary to gain the competitive advantages, and 2) exploring supply chain opportunities, which is about understanding which combination of suppliers is likely to render superior performances in terms of package quality.

\subsection{Lessons learned and proposed way forward}

Two main lessons learned emerging during the creation of the model-driven environment relate to data availability and maturity of the models.

Firstly, it shall be noticed that, while some models are fully developed and have achieved a good level of accuracy, other models in the chain do not feature the same degree of maturity and are still in building phase. One example is the lamination model at Packaging Material level, which is not yet fully developed because of the complexity of adhesive bonding, which makes computation time to be significant. Importantly, in the proposed framework statistical/virtual engineering models and physical models are intended to feed each other when new data are obtained, to increase fidelity and quality of the simulation over time. Nowadays, the challenge is not only to make the virtual model more realistic, but also to reduce computation time. For some aspects of the product, which is, for instance, with regards to structural integrity, simulations might require days or even weeks to produce results. The use of response surface methodology or surrogate modelling techniques is therefore highly interesting to enable the effective implementation of the proposed framework.

A major problem with value assessment, especially in a preliminary phase, is that the underlying models vary a lot in terms of quality and reliability, which is they are built on knowledge with a low degree of maturity. This degree of uncertainty needs to be handled by assisting designers and decision makers in achieving a better understanding of what those uncertainties, ambiguities, and assumptions involved. In other words, designers need to know which is the level of maturity (Johansson et al., 2011) of the knowledge upon which the models, and thus value assessment, are built. It is critical to have pointers that indicate to what extent people may trust the material entering in the assessment activity. Models able to communicate reliability and maturity of this information have been advocated as a major enhancement to support the visualization of value. One way to assess the maturity level of each model is to measure by how much it deviates (in percentage) from the available physical counterpart, but this is not always feasible. A possible way forward is that of conceptualizing a design support for improving confidence and validity in models, by communicating uncertainties from modelling and simulation to relevant stakeholder, as proposed by Johansson et al. (2017).

\section{Conclusions}

The paper presents and discusses an assessment framework to support collaborative decision making in cross-functional teams dealing with the design of innovative food packaging material configurations. The proposed model-driven environment is intended to connect high-level aspects of value with simulations and analysis conducted on the mechanical properties of the hardware.

The presented results are considered a step forward toward a larger research effort whose purpose is to create a model-driven platform for value-based decisions in conceptual design. The purpose is to use models to capture and represent 'value' aspects and link these to the engineering design process. While continuing with the development of the above-described value modelling environment, future research 
will also feature 'few-focused case studies' to overcome the limitations of the single-case study approach. Enlarging the number of cases will allow to further build theory on the topic of value-driven engineering design, identifying key variables, describing their linkages and why relationships exist. An interesting track for future developments is related to the use of data mining techniques to support decision makers in discovering patterns and making predictions. Developing capabilities to organize such patterns would greatly enhancing the reliability and fidelity of value models at all levels.

\section{Acknowledgements}

The research leading to these results has received financial support by the Swedish Knowledge and Competence Development Foundation (Stiftelsen för kunskaps- och kompetensutveckling) through the Model Driven Development and Decision Support research profile at Blekinge Institute of Technology.

\section{References}

Andreasson, E. and Jönsson, J. (2014), “Advancements in package opening simulations”, Procedia Materials Science, Vol. 3, pp. 1441-1446. https://doi.org/10.1016/j.mspro.2014.06.233

Bertoni, M., Bertoni, A. and Isaksson, O. (2018a), "Evoke: A value-driven concept selection method for early system design", Journal of Systems Science and Systems Engineering, Vol. 27 No. 1, pp. 46-77. https://doi.org/10.1007/s11518-016-5324-2

Bertoni, M., Wall, J. and Bertoni, A. (2018b), "Model-Driven Decision Arena: an aerospace study", Proceedings of the DESIGN 2018 / 15th International Design Conference, Dubrovnik, Croatia, May 21-24, 2018, The Design Society, Glasgow.

Blessing, L.T. and Chakrabarti, A. (2009), DRM: A Design Research Methodology, Springer London. https://doi.org/10.1007/978-1-84882-587-1

Cheung, J., Scanlan, J., Wong, J., Forrester, J., Eres, et al. (2012), “Application of value-driven design to commercial aeroengine systems", Journal of Aircraft, Vol. 49 No. 3, pp. 688-702. https://doi.org/10.2514/1.C031319

Coles, R., McDowell, D. and Kirwan, M.J. (2003), Food packaging technology, Vol. 5, CRC Press.

Eres, M.H., Bertoni, M., Kossmann, M. and Scanlan, J. (2014), "Mapping customer needs to engineering characteristics: an aerospace perspective for conceptual design", Journal of Engineering Design, Vol. 25 No. 1-3, pp. 64-87. https://doi.org/10.1080/09544828.2014.903387

Isaksson, O., Bertoni, M., Hallstedt, S. and Lavesson, N. (2015), "Model Based Decision Support for Value and Sustainability in Product Development", Proceedings of the 20th International Conference on Engineering Design - ICED 2015, The Design Society, Milan, pp. 21-30.

Isaksson, O., Larsson, T.C. and Rönnbäck, A.Ö. (2009), "Development of product-service systems: challenges and opportunities for the manufacturing firm", Journal of Engineering Design, Vol. 20 No. 4, pp. 329-348. https://doi.org/10.1080/09544820903152663

Islam, M. S., Kao-Walter, S. and Yang, G. (2016), "Study of Ligament Length Effect on Mode Mix of a Modified In-Plane Shear Test Specimen", Materials Performance and Characterization, Vol. 5 No. 3, pp. 249-259. https://doi.org/10.1520/MPC20150058

Johansson, C., Wall, J. and Panarotto, M. (2017), "Maturity of models in a multi-model decision support system", Proceedings of the 21 st International Conference on Engineering Design (ICED), Vancouver, Canada, August 21-25, The Design Society, Glasgow.

Johansson, C., Hicks, B., Larsson, A.C. and Bertoni, M. (2011), "Knowledge maturity as a means to support decision making during product-service systems development projects in the aerospace sector", Project Management Journal, Vol. 42 No. 2, pp. 32-50. https://doi.org/10.1002/pmj.20218

Krikelis, A. and Weems, C.C. (1994), "Associative processing and processors", Computer, Vol. 27 No. 11, pp. 12-17.

Leavy, B. (2010), "Design thinking-a new mental model of value innovation", Strategy and leadership, Vol. 38 No. 3, pp. 5-14.

McManus, H.M., Richards, M.G., Ross, A.M. and Hastings, D.E. (2007), "A Framework for Incorporating "ilities" in Tradespace Studies”, AIAA SPACE 2007 Conference \& Exposition, Long Beach, Vol. 1, pp 941-954.

Miles, M.B., Huberman, A.M. and Saldana, J. (2013), Qualitative data analysis: A methods sourcebook, SAGE Publications, Incorporated.

Nygårds, M., Just, M. and Tryding, J. (2009), "Experimental and numerical studies of creasing of paperboard”, International Journal of Solids and Structures, Vol. 46 No. 11-12, pp. 2493-2505. https://doi.org/10.1016/j.ijsolstr.2009.02.014 
Osterwalder, A., Pigneur, Y., Bernarda, G., and Smith, A. (2014). Value proposition design: How to create products and services customers want, John Wiley \& Sons.

Pahl, G. and Beitz, W. (1996), Engineering Design: A Systematic Approach, Springer, Berlin. https://doi.org/10.1007/978-1-4471-3581-4

Panarotto, M., Wall, J. and Larsson, T. (2017), "Simulation-driven design for assessing strategic decisions in the conceptual design of circular PSS business models", Procedia CIRP, Vol. 64, pp. 25-30. https://doi.org/10.1016/j.procir.2017.03.026

Price, M., Soban, D., Mullan, C., Butterfield, J., and Murphy, A. (2012), "A novel method to enable trade-offs across the whole product life of an aircraft using value driven design", Journal of Aerospace Operations, Vol. 1 No. 4, pp. 359-375.

Ritchie, J., Lewis, J., Nicholls, C. M. and Ormston, R. (2013), Qualitative research practice: A guide for social science students and researchers, Sage.

Rundh, B. (2009), "Packaging design: creating competitive advantage with product packaging", British Food Journal, Vol. 111 No. 9, pp. 988-1002. https://doi.org/10.1108/00070700910992880

Sand, C. (2010), The packaging value chain, DESteck Publications, Inc.

Sellgren, U. (2004), "Question-driven modelling”, Proceedings of the DESIGN 2004 / 8th International Design Conference, Dubrovnik, Croatia, May 17-20, 2004, The Design Society, Glasgow, pp. 245-258.

Singh, P., Saengerlaub, S., Abas Wani, A. and Langowski, H.C. (2012), "Role of plastics additives for food packaging", Pigment and Resin Technology, Vol. 41 No. 6, pp. 368-379. https://doi.org/10.1108/03699421211274306

Thomke, S. and Fujimoto, T. (2000), "The effect of "front-loading" problem-solving on product development performance", Journal of Product Innovation Management, Vol. 17 No. 2, pp. 128-142. https://doi.org/10.1111/1540-5885.1720128

Wang, S.T.E. (2013), "The influence of visual packaging design on perceived food product quality, value, and brand preference", International Journal of Retail and Distribution Management, Vol. 41 No. 10, pp. 805-816. https://doi.org/10.1108/IJRDM-12-2012-0113

Willard, B. (2012), The new sustainability advantage: seven business case benefits of a triple bottom line, New Society Publishers, Gabriola Island, BC.

Wyrwa, J. and Barska, A. (2017), "Packaging as a Source of Information about Food Products", Procedia Engineering, Vol. 182, pp. 770 - 779. https://doi.org/10.1016/j.proeng.2017.03.199

Yin, R.K. (2013), Case study research: Design and methods, Sage publications.

Zanakis, S.H., Doukidis, G. and Zopounidis, C. (2013), Decision Making: Recent Developments and Worldwide Applications, Vol. 45, Springer Science and Business Media.

Marco Bertoni, Associate Professor

Blekinge Institute of Technology

SE-371 79 Karlskrona, Sweden

Email: marco.bertoni@bth.se 